\title{
Do discurso oficial ao discurso didático-pedagógico: os (des)caminhos da inclusão das histórias e das culturas indígenas no cenário educacional brasileiro
}

\author{
From the official discourse to didactic-pedagogical discourse: (dis) ways of \\ including indigenous histories and cultures in the Brazilian educational scene \\ Icléia Caires Moreira ${ }^{1}$ \\ Universidade Federal de Mato Grosso do Sul
}

\begin{abstract}
- RESUMO: Este trabalho objetiva problematizar o documento final da $33^{\text {a }}$ Convenção sobre a proteção e promoção da Diversidade das Expressões Culturais, a lei 11.645/08 e 3 produções didáticas sobre os indígenas organizadas de modo a consolidar o discurso oficial no discurso pedagógico. Partimos da hipótese de que essas materialidades e os seus entrecruzamentos discursivos possibilitam a (re)construção e /ou a (re)significação do processo de colonização e de desejo de controle por parte daqueles que tem o poder de estatizar uma possível representação da subjetividade em relação aos povos indígenas e seus patrimônios culturais. Para tanto, pautamo-nos, de forma transdisciplinar, no assentamento teórico-metodológico: da Análise do Discurso de origem francesa (PÊCHEUX, 1988; ORLANDI, 2008-2013; CORACINI, 2007-2016; GUERRA, 2016); da Arqueogenealogia foucaultiana $(1988,1997)$; e da visada pós-colonialista (MIGNOLO, 2003; SANTOS, 2004; 2013; NOLASCO, 2016) para refletir e observar como se delineiam modos de subjetivação dos traços identitário-culturais do indígena nas materialidades eleitas, cujo intento é dar-lhes visibilidade diante da sociedade hegemônica sob a chancela da inclusão.
\end{abstract}

- PALAVRAS-CHAVE: Discurso oficial. In-exclusão. Indígenas.

- ABSTRACT: This paper aims to problematize the final document of the 33rd Convention on the Protection and Promotion of Diversity of Cultural Expressions, Law 11.645 / 08 and 3 didactic productions on indigenous organized in order to consolidate the official discourse in the pedagogical discourse. We start from the hypothesis that these materialities and their discursive interrelationships enable (re) construction and / or (re) signification of the process of colonization and desire for control by those who have the power to nationalize a possible representation of subjectivity in Relation to indigenous peoples and their cultural heritage. In order to do so, we set ourselves, in a transdisciplinary way, in the theoretical-methodological settlement: Discourse Analysis of French origin (PECHEUX, 1988; ORLANDI, 2008-2013; CORACINI, 2007-2016; GUERRA, 2016); Of Foucauldian Archeogenealogy (1988, 1997, 2013); (MIGNOLO, 2003; SANTOS, 2004; NOLASCO, 2016) to reflect and observe how forms of subjectivation of the identitary-cultural traits of the indigenous are delineated in the elected materialities, whose intention is to give visibility to them Of hegemonic society under the seal of inclusion.

- KEYWORDS: Official speech. In-exclusion. Indigenous peoples.

\section{Introdução}

É sabido que o discurso é uma forma de ação no mundo, por meio das práticas discursivas os sujeitos constroem sua realidade social e direcionam sua maneira de pensar e agir conforme as condições sócio-históricas e as relações de poder nas quais estão submersos. Neste processo, o discurso é marcado pela ordem, regras, normas,

\footnotetext{
${ }^{1}$ Doutoranda em Estudos Linguísticos, na linha de pesquisa Discurso, Subjetividade e Ensino de Línguas, na Universidade Federal de Mato Grosso do Sul, campus de Três Lagoas, sob a orientação da Profa. Dra. Vânia Maria Lescano Guerra. icamoreira@hotmail.com
} 
construídas de forma anônima, em busca do cuidado de interesses, orientações comportamentais, atitudes e sentidos possíveis em um determinado momento históricosocial (CORACINI, 2007-2016).

Desde quando os europeus aqui aportaram, em 1500, por acaso e para o ocaso das comunidades indígenas, trazendo para o território que hoje denominamos brasileiro o projeto de concatenação das Américas, de expansão da hegemonia ocidentalista (MIGNOLO, 2003-2005-2008), instituiu-se, social e discursivamente, uma necessidade de se proteger os indígenas, dar-lhes uma fé, salvar-lhes a alma e civilizá-los (GUERRA, 2016).

Nessa esteira reflexiva, lançamos questionamentos como: protege-los de quê? De quem? E por quê? Sabemos que tais perguntas retóricas nos levarão a pensar no próprio desenrolar do processo colonial. Uma vez que é a própria sociedade hegemônica que para se estabelecer os situaram em lugares de subalternidade, de submissão e de exclusão. Desde a tomada do território brasileiro é o Estado quem dita leis e impõe suas condições para organizar a sociedade conforme seus interesses políticos e econômicos, baseados em questões capitalistas.

É sob esta égide, que buscamos problematizar o documento final da $33^{\mathrm{a}}$ Convenção sobre a proteção e promoção da Diversidade das Expressões Culturais ratificado pelo Decreto Legislativo 485/06, a lei 11.645/08 (instituidora da obrigatoriedade do ensino das culturas e histórias indígenas nas redes de ensino brasileiras) e três produções didáticas sobre os indígenas organizadas de modo a consolidar o discurso oficial no discurso pedagógico.

Para tanto, pautamo-nos, de forma transdisciplinar, no assentamento teóricometodológico: da Análise do Discurso de origem francesa (PÊCHEUX, 1988; ORLANDI, 2008,2013; CORACINI, 2007-2015; GUERRA, 2016); da Arqueogenealogia foucaultiana $(1988,1997,2013)$; e da visada pós-colonialista (MIGNOLO, 2003, 2005, 2008; SANTOS, 2007, 2013; NOLASCO, 2016) para refletir e observar como se delineiam modos de subjetivação dos traços identitário-culturais do indígena nas materialidades eleitas, cujo intento é dar-lhes visibilidade diante da sociedade hegemônica sob a chancela da inclusão.

Nossa hipótese é de que essas materialidades e os seus entrecruzamentos discursivos possibilitam a (re)construção e /ou a (re)significação do processo de colonização e de desejo de controle por parte daqueles que tem o poder de estatizar uma possível representação da subjetividade em relação aos povos indígenas e seus patrimônios culturais.

De forma específica, neste artigo, pretendemos analisar a partir da perspectiva discursiva e do processo de referenciação linguística como são construídas as representações sociais de terra, cultura e exclusão que perpassam a escritura da $33^{\mathrm{a}}$ Convenção sobre a proteção; Apontar por meio de recortes discursivos e da sondagem das formações discursivas que os atravessam os possíveis efeitos de in-exclusão e discriminação erigidos do processo de colonialidade do poder sobre o indígena e sua cultura perante a sociedade; Perscrutar como o discurso oficial da $33^{\mathrm{a}}$ Convenção sobre a proteção e promoção da Diversidade das Expressões Culturais é implementado para contribuir como artifício de instituição de consensos sociais; Historicizar os acontecimentos discursivos, na ânsia de compreender como são constituídos os discursos oficiais e didático-pedagógicos sobre os sujeitos indígenas por parte do branco ao se deparar com práticas e valores sociais diferentes dos desenvolvidos pela sociedade hegemônica; Problematizar a partir da noção de interdiscurso, no bojo da Análise de Discurso, as representações a respeito do indígena construídas pela esfera jurídicoadministrativa e educacional. 
E partir disso, podermos dizer que a investigação acerca do modo como o sujeito indígena é enunciado, representado, nesse campo do saber, imbui-se de relevância e pertinência, na medida em que, na contemporaneidade, os discursos circunscritos a práticas inclusivas ganham espaço nas esferas públicas que têm mais visibilidade aos olhos da sociedade.

\section{Condições de produção}

A partir da matriz representativa de que o indígena era um sujeito acometido de vulnerabilidade, selvagem, amistoso, inaugurada pelo acontecimento discursivo da carta de Pero Vaz de Caminha à corte portuguesa (LIMBERTI, 2012), construiu-se por meio do primeiro discurso oficial a respeito da terra e do outro, o estereótipo de que os sujeitos que aqui habitavam necessitavam da tutela lusitana, da subjugação de suas condutas às regras e normas da sociedade colonial. "Ação "impensada" desencadeou um processo de aculturação unilateral que teve como resultado de dizimação das nações indígenas através do tempo e que pode ser classificado como truculento" (LIMBERTI, 2012, p.16).

Observamos que o Estado dentro da História situa-se no entre-lugar de "algoz e salvador"; o mesmo que instituiu políticas de dizimação, hoje lança mão de leis e decretos que visam (re)parar os danos que ele mesmo causou, para amenizar os séculos de menosprezo a que os povos indígenas foram relegados (MELO, 2005), para dar cidadania, hospedar no seio social os que aqui já viviam antes dos brancos chegarem (CORACINI, 2011) em sua própria casa.

Se antes a intenção era homogeneizar para ter o controle (MIGNOLO, 2003), civilizar o indígena, segundo Castro-Gómez (2005) a reorganização global da economia capitalista, atualmente, se apoia na produção das diferenças, não para celebrá-las, ou subverter o sistema, mas para contribuir com sua consolidação. O Estado funciona como uma instância central garantindo a organização racional da vida humana sintetiza todos os interesses encontrados na sociedade. É um locus capaz de formular metas válidas a todos, analisa desejos, interesses e emoções direcionadoras dos sujeitos rumo às metas por Ele definidas. Por meio das ciências sociais e suas consequências práticas, legitima suas políticas reguladoras, cria perfis de subjetividade estatalmente coordenados, instituindo, dessa maneira, um processo de "invenção do outro" por meio de dispositivos de saber-poder que funcionam como o cerne da construção de representações.

Nas palavras de Gregolin (2007), essas representações só podem ser agenciadas pela inefável articulação entre o linguístico e o social. Portanto, o sujeito (re)produz e é (re)produzido por estratégias (micro)capilares que são mobilizadas pelos discursos, como práticas que abalizam o governo de si e o dos outros conforme os interesses latentes na sociedade (FOUCAULT, 2013).

A partir desse quadro, é possível articular que o discurso oficial da $33^{\mathrm{a}}$ Convenção sobre a proteção e promoção da Diversidade das Expressões Culturais (ratificada pelo governo brasileiro em 2006 por meio do decreto legislativo 485), da lei 11.645/08 (responsável pela instituição da obrigatoriedade do ensino das histórias e culturas indígenas no ensino básico brasileiro) e o discurso didático-pedagógico das obras: Povos Indígenas no Brasil Mirim, publicado em 2015 pelo Instituto Socioambiental - ISA, voltado ao ensino fundamental I, Cineastas indígenas para Jovens e Crianças, publicados pela ONG Vídeos nas Aldeias - VNA em 2010, direcionado ao ensino fundamental II e Povos indígenas do Brasil: uma história de resistência produzida pela editora IMEPH em 2010 para o ensino médio entrelaça-se e entretecem- 
se para formar uma trama de dizeres que funcionam como espaço de formatação da representação identitária dos sujeitos indígenas, cujos discursos tornam-se modos de subjetivação (FOUCAULT, 1997), como "verdades irrefutáveis".

Em conformidade com Foucault (2013), articulamos que tanto a esfera jurídica quanto o sistema pedagógico tornam-se uma maneira política e estratégica de manter ou modificar a apropriação dos discursos do/sobre os sujeitos, vinculados por saberes e poderes que eles trazem em seu bojo.

O diálogo entre o texto da lei, o texto final da $33^{\mathrm{a}}$ convenção sobre a Diversidade Cultural e as a produções didáticas eleitas, que trazem narrativas, comentários, imagens e escritas de si de sujeitos indígenas e informações sobre diversas etnias, nos possibilitará (d)enunciar e problematizar a instauração de construções discursivas que emergem deste cenário e circulam a respeito dos sujeitos indígenas, já que todas as materialidades mobilizam formação de saberes instituindo práticas discursivas e sociais de sentidos.

Na percepção de Fonseca (1999), os materiais didáticos e o processo educativo formal não estão deslocados do contexto político e cultural e das relações de dominação jurídico-administrativas, tornando-se, muitas vezes, instrumentos utilizados para legitimação de sistemas de poderes, além de formas representativas de universos culturais específicos. Atuam como dispositivos mediadores entre concepções e práticas políticas e culturais, instituindo-se como elementos importantes da engrenagem de manutenção de determinadas representações.

Nesse percurso reflexivo, é possível ver que as políticas públicas inclusivas ligadas à diversidade cultural surgem, discursivamente, por meio de ações mobilizadas por agentes internacionais, relações vinculadas a interesses capitalistas e da criação de leis que constituem uma rede de controle dos sujeitos e dos sentidos a eles atribuídos. Nesse aspecto, a vida do sujeito na sociedade atual passa pela esfera da administração da subjetividade controlada e contida. Os sujeitos à margem são introduzidos na dinâmica social via políticas de inclusão e respeito à diversidade cultural a fim de darlhes a sensação de integração a esse sistema socioeconômico, para que se vejam reconhecidos, valorizados e atinjam um "ideal de eu social" sancionado pelo Estado. (DIAS, 2010).

Segundo a autora, esse discurso da in/exclusão não é novo. Desde os séculos XVII e XVIII, ele vem sendo utilizado como meio de validação daquilo que o homem não consegue justificar, ou seja, suas atitudes de repulsa ao outro diferente. E o diferente é aquele que não se encontra dentro das normas estabelecidas por um determinado tipo de poder, que o Estado precisa capturar para que se instituam ações capazes de regular, enquadrar, incluir, disciplinar e educar (DIAS, 2010).

Neste ínterim, é preciso que nos comprometamos em analisar os processos de transculturação pelo viés do pensamento pós-colonial, para indagar sobre a representação da diferença para ultrapassar esta noção e descontruirmos os binômios estereotipantes produzidos pelo discurso do poder, "reflexo de traços culturais ou étnicos preestabelecidos, inscritos na lápide fixa da tradição" (BHABHA, 2013, p. 21).

Por meio das considerações descritas, mobilizamos que o gesto analítico discursivo a respeito da representação do indígena, nos permitirá tecer deslocamentos, reflexões críticas e problematizadoras que levem a compreender o processo de subjetivação da alteridade do sujeito indígena tanto no discurso oficial quanto em sua materialização em aparatos didáticos disponíveis na esfera pública e distribuídos no cenário educacional. Além de possibilitar denunciar como são construídas discursivamente as identificações/representações daqueles que o discurso hegemônico insiste em posicioná-los sempre do lado de lá da fronteira (SANTOS, 2004). 


\section{O entrelaçar dos fios teóricos}

A constituição de um gesto analítico em Análise do Discurso (AD) necessita utilizar-se da construção de um artifício teórico próprio em razão das problematizações que emergem do corpus a ser estudado, sobretudo pelas condições de produção específicas em que tais discursos se constituíram no jogo da linguagem. A AD nos possibilita compreender que um plano discursivo articula linguagem, sociedade e contexto ideológico, permite que lancemos um olhar diferenciado sobre as práticas linguageiras (ROCHA e DEUSDARÁ, 2005).

Por esta razão, explicitamos que construção do dispositivo teóricometodológico não se baseará em conceitualizações feitas a priori, pois estas vão entrelaçar-se e entretecer-se como fios de uma trama, de uma rede transdisciplinar e híbrida (CORACINI, 2007-2016), mediante as emergências dos sentidos, das regularidades, das formações discursivas, do interdiscurso, da enunciação, que emanarem do corpus eleito, para que não acabemos por (re)cair na aplicação de noções conceituais tidas como verdades estanques, camisas de força teórico-metodológicas.

Esse diálogo entre distintas áreas do saber se concatena, epistemologicamente, pelo fato de que as materialidades linguísticas podem trazer em seu bojo discursos que exijam do analista buscar outras possibilidades de interpretações que, por vezes, a própria análise do discurso possa não vir a abranger. Nesta esteira, a articulação transdisciplinarizada de conceitos da Análise do Discurso de orientação (PÊCHEUX, 1988; ORLANDI, 2008-2010-2013; CORACINI, 2007-2015; GUERRA, 2016); da Arqueogenealogia foucaultiana $(1988,1997)$; e da visada pós-colonialista (MIGNOLO, 2003; SOUSA SANTOS, 2007; 2013; NOLASCO, 2016) possibilita-nos a construção de um dispositivo orientador de nossa reflexão analítica.

Baseados nos estudos discursivos sabemos que os sujeitos se encontram submersos em um contexto sócio histórico constituído na/pela linguagem em que coabitam entrecruzam-se e entrelaçam-se inumeráveis vozes, dizeres e silenciamentos (CORACINI, 2007). Nesse espaço discursivo é que se constituem as representações identitárias dos sujeitos. Poderes e saberes são mobilizados estrategicamente, em (micro)capilaridades, abalizando o governo dos sujeitos na malha social.

A partir disso podemos dizer que a linguagem é o lugar de celebração de formulações e movências sociais, históricas e ideológicas. Neste aspecto, buscamos ponderar a respeito da emergência de uma rede de sentidos oficiais e pedagógicos que operam em conjunto e torna a escola, espaço institucional vinculada ao Estado, um locus formatador e normalizador de identidades, via estratégias de saber-poder, que buscam fossilizar certas representações dos sujeitos perante a sociedade.

Sob este prisma teórico, a formulação de um documento final referente a uma Reunião que visa proteger e promover a diversidade cultural, a promulgação de uma lei, cujo ideal é a obrigatoriedade do ensino de culturas e histórias indígenas nas escolas e em consonância com estes documentos oficiais a produção de obras por parte de diversas instituições que visem atender a esta demanda estatal como um suporte de veiculação de informações, a respeito de traços e marcas identitárias de diversas etnias indígenas acabam por funcionar como instrumentos de construção da representação do próprio sujeito-indígena, no imaginário social brasileiro.

Articulando com Castro-Gómez (2005) podemos dizer que o processo de reorganização global da economia capitalista contemporânea está apoiado na produção das diferenças, não para celebrá-la ou para a subversão do sistema, mas para contribuir com sua consolidação e disseminação de preconceitos de toda ordem. Neste sentido, é 
relevante que consideremos que o Estado funciona como uma instância central garantidora da organização racionalizada da vida humana, como um locus social capaz de formular metas válidas a todos direcionadoras dos sujeitos rumo a metas por ele definidas. É via ação estatal que são legitimadas às políticas reguladoras, criadoras de perfis de subjetividade estatalmente coordenados, instituindo, desta maneira, um processo de "invenção do outro" por meio de dispositivos de saber-poder, cerne da construção de representações dentro de suas instituições, nesse caso em específico o ambiente escolar.

Destarte, a distribuição nas escolas de ensino público e/ou a disponibilização no mercado de materiais didáticos, sobre o sujeito indígena se constitui em um instrumento poderoso que tanto pode favorecer a discriminação e a exclusão quanto a ampliação dos limites humanos que abriguem, cada vez mais, a diversidade a depender de quais discursos materializam-se nesse suporte, que tipo de formações discursivas os mobilizam, no percurso (de)lineador da representação do indígena.

Nesse segmento, podemos dizer que a escrita é instrumentalizadora da construção de leis e de identidades, planeja programas, organiza a compreensão do mundo no que se refere à inclusões e exclusões, viabilizada por meio de instituições legitimadas, neste caso as escolas, e pelos discursos hegemônicos, materializados em tratados, manuais, ou guias didáticos, regulamentam a conduta dos atores sociais, estabelecendo fronteiras entre os sujeitos, o que acarreta na construção de uma verdade que existe um "dentro ou fora dos limites definidos por essa legalidade escriturária".

As práticas discursivas filiadas a formações discursivas coloniais implementadas por meio dessa taxonomia pedagógica, em lugar de incluir/unir, acaba por reforçar a separação entre branco e indígena. Conforme Quijano (2005) configuramse como um aparato legitimador de um imaginário estabelecedor de diferenças incomensuráveis entre colonizador/branco e colonizado/indígena, em que noções de "raça e cultura" funcionam como dispositivos geradores de identidades opostas.

\section{Uma incursão Analítica:}

A fim de representar esta gama de questões articuladas anteriormente, trazemos à baila $\mathrm{R} 1$, recorte extraído da página 3 do documento final da $33^{a}$ Convenção sobre a proteção e promoção da diversidade das expressões culturais, evento promovido pela UNESCO (organização das nações Unidas) de 03 a 21 de outubro de 2005, cujo texto oficial foi ratificado pelo Brasil no ano seguinte por meio do decreto 485/2006. Vejamos:

\footnotetext{
R1: A proteção e a promoção da diversidade das expressões culturais pressupõem o reconhecimento da igual dignidade e o respeito por todas as culturas, incluindo as das pessoas pertencentes a minorias e as dos povos indígenas. (p. 3, artigo 2 - Princípios diretores, Grifos nossos).
}

O documento do qual foi extraído este excerto foi organizado em 7 grandes itens, a saber: I Objetivos e princípios diretores, II Campo de Aplicação, III Definições, IV Direitos e Obrigações das Partes, V relações com outros instrumentos, VI órgãos da convenção, VII Disposições finais. O fragmento eleito faz parte do item I Objetivos e princípios diretores, mais especificamente, está presente no artigo II princípios diretores, como descrição do terceiro princípio elencado pela UNESCO: da igual dignidade e do respeito por todas as culturas.

Ao lançarmos nosso olhar sobre a materialidade discursiva em análise podemos dizer que já em suas primeiras linhas encontramos o substantivo feminino "Proteção" 
que segundo Ferreira (2009, p. 661) significa ato ou efeito de proteger, que por sua vez, significa dispensar proteção, amparar, favorecer, defender, preservar do mal.

Se for preciso que se proteja uma ou diversas culturas, poderíamos retomar as questões lançadas na introdução deste artigo: protege-los de quê? De quem? E por quê? Como? Preservá-las de que mal? Ao refletirmos sobre tais questões por meio deste item lexical temos a possibilidade de interpretar que a organização de fomento permite emergir de por meio de seu dizer que a cultura hegemônica, ocidentalista, desde os primórdios da humanidade persegue e dizima culturas diferentes de si. Nesta esteira de sentidos, podemos depreender do processo de enunciação o primado do interdiscurso a produzir sentidos a partir da seleção, formulação e circulação do dizer que como em uma trama se encontra entretecido e entrelaçado a dizeres outros já fossilizados na história e na sociedade.

Ao observarmos o termo "promoção" que significa ato ou efeito de promover, elevar a uma categoria superior (FERREIRA, 2009, p. 659), também nos é permitido, intradiscursivamente, interpretar que só se promove o que estava em escala inferiorizada, subalterna. Desta forma, vemos emergir do excerto às formações discursivas da in-exclusão e colonialidade que se digladiam em um conjuramento que envolve questões de históricas e capitalistas. Sabemos que, via interdiscurso, que o processo de colonialidade instaurou entre os povos um estado de polarização que elevou a cultura europeia ao centro e relegou ao silêncio e a subalternidade as demais culturas a quem ela se sobrepôs para levar a cabo sua demanda expansionista (MIGNOLO, 2003).

A partir deste quadro, podemos dizer com Mignolo (2003) que o sistema mundial nasceu no séc. XVI com a "descoberta" das Américas, por meio da tomada deste território o sistema mundial se estabeleceu tendo por base a economia capitalista e exploratória. Desse processo emergiu a colonialidade do poder que sublinha a organização geoeconômica do planeta e questões capitalistas, raciais e trabalhistas. A "missão civilizadora" vem como uma forma de organização e coerção conduzir e agenciar a vida das pessoas e fluxo produtivo planetário, baseada em binarismos trabalha pelo viés da hierarquização e inferiorização do outro para estabelecer-se. A dominação colonial erigia-se em um complexo cultural a partir da racionalidade e estabelecia-se como o paradigma universal do conhecimento.

Ao levarmos em consideração estas questões, vemos que a busca pelo "reconhecimento da igual dignidade e o respeito por todas as culturas" nos remete ao desejo de remediar anos a fio de processos de exclusão, inferiorização das demais culturas por parte da hegemonia branca, que se estabeleceu a partir do "conhecimento" ocidentalizado dos humanistas dos séculos XV e XVI. Tais conjecturas acabaram por concluir que os povos autóctones eram sub-humanos, sem alma, ideia que amparou o conceito de vazio jurídico e justificou a invasão e ocupação dos territórios indígenas e a dizimação das etnias, coibindo o uso da língua e cultura local. Se há a necessidade de pôr em prática um princípio que (re)conhece e que visa dar "igual dignidade e respeito" as culturas existentes é porque mesmo que se saiba da multiplicidade de formas culturais dos povos em escala mundial, ainda há aqueles que não estão alinhados no patamar de igualdade e que não recebem o respeito de forma a equiparar-se a outros.

Nesse ínterim, problematizamos a utilização do pronome indefinido "todas" pretendendo criar um efeito de totalidade de generalidade para o substantivo "culturas", de modo a estabelecer uma relação de igualdade e abrangência entre elas. Situação ilusória, que em seguida é acompanhado de uma gradação classificatória, cuja emergência (d)enuncia que neste "todas" não estariam inclusas nem as minorias, nem os povos indígenas, uma vez que o sujeito enunciador necessita demarcar após uma vírgula, aqui compreendida como uma fronteira entre cá (hegemonia) e lá (margem) 
(SANTOS, 2004) a necessidade de complementar seu dizer com "incluindo as das pessoas pertencentes a minorias e as dos povos indígenas", colocando no mesmo patamar de exclusão tanto as minorias quanto os povos indígenas e suas formas culturais de inscrição no campo do simbólico. Ambos relegados ao locus periférico, subalterno e fora da legalidade escriturária.

Podemos ainda dizer, que ao valer-se do verbo incluir, no gerúndio, "incluindo", marcador de processos na escala de implementação de ações verbais (NEVES, 2011), o enunciador deixa escapar do/no seu dizer que precisam ser incluídos, porque foram e ainda são alvo da exclusão, da discriminação, da falta de respeito para com suas pessoas e culturas, acometidos de preconceito por parte da cultura hegemônica. Toda essa conjuntura se organiza estrategicamente, via formas microcapilares de poder-saber sobre o outro (FOUCAULT, 2015), porque a humanidade moderna não se conceberia sem uma sub-humanidade moderna. Para ser superior, era necessário que algo fosse, em contrapartida, inferiorizado (MIGNOLO, 2005).

A negação de uma parte da humanidade constituiu e ainda constitui a condição para a outra parte da humanidade se afirmar. Segundo Santos (2004), esta tese hoje é tão verdadeira quanto no período colonial. O pensamento moderno ocidental continua a atuar por meio de linhas abissais divisoras do mundo humano e do sub-humano. As colônias representam um modelo de exclusão radical atualizado hoje no pensamento em práticas modernas ocidentais hegemônicas. $\mathrm{O}$ enunciador tenta operacionalizar seu dizer dito de inclusão inscrito em um desejo de univocidade, de monossemia, entretanto, podemos dizer que o discurso foge da sua competência formulativa e ecoa em sua opacidade dando margem a polissemia, autorizando outras significações medicante ao entrelaçamento com as condições históricas e ideológicas circulantes (PÊCHEUX, 1988).

As linhas abissais globais não são fixas, mas historicamente, sempre foram vigiadas e guardadas de modo a manterem centro e margem delimitados em seus respectivos status de poder. Suas bases ficaram estremecidas com a evolução dos processos de independência e anticoloniais. O outro lado da linha rebelou-se diante da exclusão radical a medida que os povos relegados ao paradigma da apropriação/violência se organizaram e conclamaram o direito a inclusão no paradigma da regulação/emancipação (SANTOS, 2004). Por um período, pareceu que as linhas abissais tinham se diluído, entretanto pode-se notar mediante os estudos pós-coloniais que isso não aconteceu, a análise de documentos oficiais como a materialidade eleita, nos permite observar que os povos indígenas ainda continuam a ser falado, o subalterno ainda não pode falar, o discurso ainda funciona pela tática de neutralização do outro, subalterno invizibilizado, expropriando-o da possibilidade de autorepresentação, relegando-o ao silenciamento (SPIVAK, 2010). Há aqui a ocorrência do processo de "invenção do outro" por meio de dispositivos de saber-poder, legitimadores de verdades, que funcionam como pontos nodais da construção de representações (CASTRO-GÓMES, 2005).

A exclusão social é sempre produto de relações de poder desiguais, estas iniciativas de criação de meios documentais e legais de intervenção sócio-política relativas a condição humana e cultural dos sujeitos, implicam o desejo da redistribuição de recursos materiais, sociais, políticos, culturais e simbólicos envolvem em simultaneidade tanto o princípio da igualdade quanto o princípio do reconhecimento da diferença (SANTOS, 2004). Mas ainda resvalam na prática de coerção e regulamentação dos modos de existência dos povos para que signifiquem dentro dos 
liames permitidos pela hegemonia e possam ser a chave do contato e estabelecimento de relações que visem questões capitalistas.

Sobressai do recorte eleito a tentativa de se assegurar um direito que não foi e ainda não é tido como prática social, contudo, podemos observar que esta ação discursiva, trabalha na contramão de seus intentos, pois dela emergem o reforço do processo de exclusão e discriminação das culturas que habitam historicamente a margem da conjuntura global. A isto podemos acrescentar que nenhum discurso, ou forma de saber estabelecido, é neutro. É por meio do jogo de marcação simbólica que se perfilam as hierarquias fomentadoras tanto da inclusão quanto da exclusão dos sujeitos via engendramento de identidades coletivas ou individuais.

A linguagem é sempre opaca, lugar do equívoco, da cultura e da ideologia, logo, da heterogeneidade (ORLANDI, 2013) por essa razão é necessários (des)confiar das obviedades e desconstruir as verdades circulantes com vistas a compreender as razões que as colocaram em um patamar de irrefutabilidade no bojo social.

\section{Considerações finais}

Considerando a hipótese e os objetivos expressos anteriormente, em consonância com as mobilizações teóricas implementadas, procuramos, neste artigo, fazer emergir um gesto de resistência intelectual para escapar às malhas da rede de um saber instituído (FOUCAULT, 1997), abrir caminho para a reflexão por meio de uma crítica nascida das nuances políticas da margem, da fronteira, da periferia para descolonizar a epistemologia e o cânone ocidental a partir de corpos e lugares étnicoraciais subalternizados (NOLASCO, 2016), para lutar por um mundo onde outros mundos sejam possíveis. De modo a (des)confiar das formas de saber circulantes que permitem a concatenação da representação do indígena e de suas culturas, tanto no cenário jurídico-administrativo quanto no educacional, como sujeitos da exclusão e da subalternidade.

E repensarmos a cartográfica e a história latino-americana por outras vias de representação, compreender os jogos da diferença, que coloquem em xeque a tradição e as relações de poder que marcaram o percurso desses povos (GUERRA e SOUZA, 2013).

Sabemos que a compreensão do mundo excede a compreensão ocidental do mundo, sob esta ótica a globalização como é vista hegemonicamente. E que esta reflexão pode ser muito maior do que de fato temos registro na linearidade ilusória da história. Quanto mais compreensões não-ocidentais forem identificadas, mais possibilidades poderão vir a ser descobertas ou geradas. Que o pensamento pós-abissal de SANTOS (2004) e tantas outras formas de problematizar as bases do sistema mundo, via pensamento latino-americano, venha nos mostrar que a diversidade é inesgotável e ainda continua desprovida de uma epistemologia adequada para compreendê-la, por que esta continua por construir como se constroem as relações entre a humanidade.

\section{REFERÊNCIAS}

BHABHA, Homi. O local da cultura. Trad. Myriam Ávila, Eliana Lourenço de Lima Reis e Glaucia Ranete Gonçalves. Belo Horizonte: Ed. UFMG, 2013.

CASTRO-GÓMES, Santiago. Ciências sociais, violência epistêmica e o problema da "invenção do outro". In: LANDER, E. (Org.). A colonialidade do saber: eurocentrismo e ciências sociais. Perspectivas latino-americanas. Ciudad Autónoma de Buenos Aires, Argentina: Clacso, 2005. p.169-186. 
CORACINI, Maria José. A celebração do outro: arquivo, memória e identidade: línguas (materna e estrangeira). Plurilinguismo e tradução. Campinas: Mercado de Letras, 2007.

- CAVALLARI, Juliana S. (Orgs.). (Des)construindo verdade(s) no/pelo material didático: discurso, identidade e ensino. Campinas: Pontes, 2016.

DIAS, Cristiane. Telecentros como políticas públicas de inclusão digital: da administração da vida na cidade. In: ORLANDI, E. (Org.). Discurso e políticas públicas urbanas: a fabricação do consenso. Campinas: RG, 2010. p. 43-73.

FOUCAULT, Michel. Microfísica do poder. Trad. Roberto Machado.11. ed. Rio de Janeiro: Graal, 1997.

A ordem do discurso. Trad. Laura F. de Almeida Sampaio, 23 ed. São Paulo: Loyola, 2013.

Vozes (des)ordenadas e (in)fames. In: MILANEZ, N.; GASPAR, N. (Orgs.). A (des)ordem do discurso. São Paulo: Contexto, 2010b. p.105-126.

GREGOLIN, Maria do R. Foucault e Pêcheux na Análise do Discurso: diálogos e duelos. São Carlos: Claraluz, 2007.

GUERRA, Vânia M. L; SOUZA, Claudete. Entre o discurso e a identidade: a emergência de uma epistemologia crítica para entender o jogo da diferença. In: NOLASCO, Edgar C.; GUERRA, Vânia M. L. O sol se põe na fronteira: discursus, gentes e terras. São Carlos: Pedro \& João, 2013. p.37-66.

. ALMEIDA, Willian D (Orgs) Povos indígenas em cena: das margens ao centro da História. Campo Grande: OMEP/BR, 2016, p.139-156.

LIMBERTI, Rita de C. P. A imagem do índio: discursos e representações. Dourados: Editora UFGD, 2012.

MELO, Patrícia. B. O índio na mídia: discurso e representação social. III Jornada Internacional e I Conferência Brasileira sobre Representações Sociais - Relações entre Práticas e Representações, Rio de Janeiro, v. 1, p. 2375-2389, 2005.

MIGNOLO, Walter. D. Histórias locais/ projetos globais: colonialidade, saberes subalternos e pensamento liminar. Trad. Solange Oliveira. Belo Horizonte: UFMG, 2003.

A colonialidade de cabo a rabo: o hemisfério ocidental no horizonte conceitual da modernidade. In: LANDER, E. (Org.). A colonialidade do saber: eurocentrismo e ciências sociais. Perspectivas latino-americanas. Ciudad Autónoma de Buenos Aires, Argentina: Clacso, 2005. p. 33-49.

Desobediência Epistêmica: a Opção Descolonial e o significado de Identidade em Política. Cadernos de Letras da UFF - Dossiê: Literatura, língua e identidade, Rio de Janeiro, nº 34, 2008, p. 287-324.

NEVES, M. H. Gramática de usos do Português. 2. ed. São Paulo: Editora Unesp, 2011.

NOLASCO, E. C. O método do discurso fronteiriço: por uma aproximação do sujeito da exterioridade. In: GUERRA, V. M. L; ALMEIDA, W. (Orgs) Povos Indígenas em cena: das margens ao centro da História. Campo Grande: OMEP/BR, 2016. p. 52-66. 
ORLANDI, E. Terra à vista - discurso do confronto: Velho e Novo Mundo. 2 ed. Campinas: Editora da Unicamp, 2008.

2013

Análise de discurso: princípios e procedimentos. 11. ed. Campinas: Pontes,

SANTOS, B. S. Para além do pensamento abissal: Das linhas globais a uma ecologia de saberes. Revista Crítica de Ciências Sociais, v 78, 3-46, 2004.

SPIVAK, G. C. Pode o subalterno falar? Trad. de Sandra Regina Goulart Almeida, Marcos Pereira Feitosa e André Feitosa. Belo horizonte: Editora UFMG, 2010. p. 23-98.

Recebido em: junho de 2017.

Aprovado em: julho de 2017.

Como citar este trabalho:

MOREIRA, I. C. Do discurso oficial ao discurso didático-pedagógico: os (des)caminhos da inclusão das histórias e das culturas indígenas no cenário educacional brasileiro. Traços de linguagem, v. 1, n. 1, p. 28-38, 2017. 